Journal of Engineering and Applied Sciences 15 (6): 1552-1557, 2020

ISSN: 1816-949X

(c) Medwell Journals, 2020

\title{
Fuzzy Logic Clustering Modeling of Surface Soil Parameters Based on Georesistivity Profiles and Geology Techniques
}

\author{
${ }^{1}$ Antarissubhi, ${ }^{1}$ Lawalenna Samang, ${ }^{1}$ Tri Harianto and ${ }^{2}$ Indrabayu \\ ${ }^{1}$ Department of Civil Engineering, Hasanuddin University, Makassar, Indonesia \\ ${ }^{2}$ Department of Informatics Engineering, Hasanuddin University, Makassar, Indonesia
}

\begin{abstract}
This research generally aims to develop a model that can simplify and streamline the investigation of surface soil work in particular knowing the characteristics of soil layers based on electrical resistivity. Problems that occur many construction failures are caused by exploitation of land use that exceeds the carrying capacity of the land, for example, the use of land originating from peat, swamps or lakes which often occurs land suddenly. Therefore, to achieve accurate soil data, a good soil investigation is needed and a georesistivity method can interpret soil properties and determine stratigraphy and characteristics of soil layers. The qualitative and quantitative research methods used consist of field research based on soil resistivity values and laboratory investigations that use conventional soil investigations as a comparison and as a reference to get detailed results on the soil layer while the results obtained from measurements on the georesistivity profile to a depth of $15 \mathrm{~m}$. Testing the results of engineering geological drilling to a depth of $15 \mathrm{~m}$, obtained 4 types of soil CH, CL, MH and ML. The results are in clusters using artificial intelligence algorithms and formed into 4 clusters which in total have 47 members.
\end{abstract}

Key words: Georesistivity, geology techniques, fuzzy c-means, geological drilling, algorithms

\section{INTRODUCTION}

There have been many failures in the construction of civil buildings in recent years due to the use of land that exceeds the carrying capacity of the land widely, for example, the use of ponds, swamps and peatlands. For housing can cause excessive decline. The characteristics of determining the right soil, it is important to design a suitable and successful in all types of construction (Cosenza et al., 2006).

The increasing number of foundation failures is often associated with a number of factors such as incomplete information about the soil and geological rocks beneath the surface of the infrastructure development site (Fatoba et al., 2010).

Geophysical exploration is basically examining the symptoms of disturbances that occur under normal conditions. This disorder can be static or dynamic, the disturbance can be created (artificial) or originating from the earth itself (natural). Static interference can affect the weight of the building that is too large. Changes in design of the soil layer due to overexploitation of certain natural resources under the layer (Reynolds, 2011). Soil has many physical and chemical properties which have a major influence on the distribution and development of vegetation and life. Preinvestigation is an important component in the design of surface infrastructure associated with risk because visual knowledge of soil conditions is limited (Danielsen and
Dahlin, 2010). The type resistivity method produces a model of soil resistivity which is related to its vertical conductivity. This method will provide the maximum information needed in the area surveyed (AL-Shuhail, 2008). The geoelectric method has advantages and disadvantages of each. One of the advantages of the geoelectric method is the non-environmentally damaging method that can be used to map and investigate the condition, type and design of surface soil bedding (Lantu et al., 2014).

Therefore, to find out the extent of harmony between the results of the geoelectrical measurement with the Wenner configuration, it is necessary to study in more detail by using the geotechnical drilling method and testing the physical properties of the soil in the laboratory. Use of geotechnical tests to define soil characteristics.

\section{MATERIALS AND METHODS}

The research methodology consists of fieldwork and laboratory investigations. The research location is in the area around the campus of the engineering faculty in Gowa district, South Sulawesi province. The field of investigation consists of electrical resistivity surveys and soil drilling. Electrical electrical sounding or 2D survey is carried out at the drill hole location BH-01, BH-02, $\mathrm{BH}-03$ and $\mathrm{BH}-04$, use simple equipment and accessories in obtaining electrical resistivity values, e.g., DC power 
sources, insulated cables, steel electrodes. Electric sounding is performed using a Wenner electrode configuration with a $3 \mathrm{~m}$ electrode distance (Siddiqui and Osman, 2012).

The method introduced by Wenner is one of the configurations that are often used in geoelectric exploration with the same spacing $\left(r_{1}=r_{4}=a\right.$ and $r_{2}=r_{3}=2 a$ ). This method provides a surface resistivity model (Telford et al., 1990). This method is used for distribution of subsurface electrical resistivity to understand groundwater conditions such as resistivity, thickness and depth. Usually, the depth of penetration is proportional to the separation between the electrodes and the variation of the electrode separation which provides information about the soil layer (Raj et al., 2015).

The distance between the drill holes is $50 \mathrm{~m}$. The process produces 2D subsoil models based on variations in resistivity and thickness of the layer. Soil samples from various depths are obtained by drilling soil using a drilling device. Four drill holes BH-01, BH-02, BH-03 and BH-04 were drilled to a depth of $15 \mathrm{~m}$, the samples obtained were taken to the laboratory. Laboratory tests were carried out on soil samples obtained from the drill holes (Siddiqui and Osman, 2012).

Fuzzy c-means: The data process is carried out to apply clustering techniques with fuzzy c-means algorithm to get the characteristics of the data. One method of clustering using the fuzzy clustering method is the fuzzy c-means algorithm which has a high degree of accuracy and fast computation.

Fuzzy c-means which determines the optimal cluster in a vector space based on the Euclidian normal form for the distance between vectors. The calculation uses fuzzy c-means with the same data but is processed with a different number of clusters, so, the results of the grouping will be slightly different because the data is not processed with only one variable but with all variables. The difference in the results of grouping is because the data in certain groups will likely move to other groups if processed with a different number of clusters (Kusumadewi and Purnomo, 2010). As the c-means algorithm the desired number of c clusters must be predetermined and the initial c clusters are needed to perform fuzzy c-means (Bezdek, 1981; Roubens, 1982).

The data technique used is using clustering techniques. This technique is used to group objects that have similarities (Jain et al., 1999).

Fuzzy c-means uses fuzzy partitions, so that, data points can belong to all groups with membership values that differ between 0 and 1 (Suganya and Shanthi, 2012). The first fuzzy c-means concept is to determine the cluster center which will mark the average location for each cluster. In the initial condition, the center of the cluster is still inaccurate, fuzzy membership determination is still randomly prioritized. Each data point has a degree of membership for each cluster. Fuzzy c-means algorithm as follows (Zimmermann, 2001).

Input data to be clustered is data $(\mathrm{X})$ in the form of matrix $\mathrm{n} \times \mathrm{m}$ $\left(\mathrm{n}=\right.$ amount of data, $\mathrm{m}=$ attribute of each data) $\mathrm{X}_{\mathrm{ij}}=$ data to-i $(\mathrm{i}=1,2, \ldots, \mathrm{n})$, attributeto-j $(\mathrm{j}=1,2, \ldots, \mathrm{m}) .(\mathrm{n} \stackrel{\mathrm{j}}{=}$ amount of data, $\mathrm{m}=$ attribute of each data)

2. Limitation

(a) Total cluster $=\mathrm{c}=4$

(b) Rank $=\mathrm{w}=2$

(c) Maximum iteration $=100$

(d) The smallest expected error $=\xi=10^{-3}$

(e) Initial objective function $=\mathrm{Po}=0$

3.Generating random numbers $\mu_{i k}, i=1,2, \ldots, n ; k=1,2, \ldots, c$; matrix elements at the beginning of $\mathrm{U}$, count the number of each column

$$
\mathrm{Q}_{\mathrm{i}}=\sum_{\mathrm{k}=1}^{\mathrm{c}} \mu_{\mathrm{ik}}
$$

With $\mathrm{j}=1,2, \ldots$, n. Count:

$$
\mu_{\mathrm{ik}}=\frac{\mu_{\mathrm{ik}}}{\mathrm{Q}_{\mathrm{i}}}
$$

4. Calculate the center of the cluster to-k : $\mathrm{V}_{\mathrm{kj}}$ with $\mathrm{k}=1,2, \ldots, \mathrm{c}$ and $\mathrm{j}$ $=1,2, \ldots, \mathrm{m}$.

$$
\mathrm{V}_{\mathrm{kj}}=\frac{\sum_{\mathrm{i}=1}^{\mathrm{n}}\left(\left(\mu_{\mathrm{ik}}\right)^{\mathrm{w}} \times \mathrm{X}_{\mathrm{ij}}\right)}{\sum_{\mathrm{i}=1}^{\mathrm{n}}\left(\mu_{\mathrm{ik}}\right)^{\mathrm{w}}}
$$

5. Calculates an objective function on iterationto-t, $\mathrm{P}_{\mathrm{t}}$ :

$$
P_{t}=\sum_{i=1}^{n} \sum_{k=1}^{c}\left(\left[\sum_{j=1}^{n}\left(X_{i j}-V_{k j}\right)^{2}\right]\left(\mu_{i k}\right)^{w}\right)
$$

6. Calculating changes in the partition matrix:

$$
\mu_{i k}=\frac{\left[\sum_{j=1}^{m}\left(X_{i j}-V_{k j}\right)^{2}\right]^{\frac{-1}{w-1}}}{\left[\sum_{k=1}^{c} \sum_{j=1}^{m}\left(X_{i j}-V_{k j}\right)^{2}\right]^{\frac{-1}{w-1}}}
$$

with $\mathrm{i}=1,2, \ldots, \mathrm{n}$ and $\mathrm{k}=1,2, \ldots, \mathrm{c}$

7. Check the stop condition:

1. if : $\left(\left|\mathrm{P}_{\mathrm{t}}-\mathrm{P}_{\mathrm{t}-1}\right|<\xi\right)$ or $(\mathrm{t}>$ Maxiter) then stop

2. if no $: t=t+1$, repeat steps to- 4

\section{RESULTS AND DISCUSSION}

Recapitulation of the results of clusters of georesistivity and engineering geology members with fuzzy c-means.

From Table 1 shows that the cluster results at the lower boundary georesistivity. Cluster 1 which represents the normalization result of the lowest limit of 0.4151 and 
J. Eng. Applied Sci., 15 (6): 1552-1557, 2020

Table 1: Results of georesistivity and engineering geology clustering

\begin{tabular}{|c|c|c|c|c|c|c|c|c|c|c|c|}
\hline \multicolumn{2}{|c|}{ Parameter } & \multicolumn{2}{|c|}{ Normalization } & \multirow{3}{*}{$\begin{array}{c}\text { Fuzzy } \\
\text { c-means }\end{array}$} & \multirow[b]{3}{*}{ Thick } & \multirow{3}{*}{$\begin{array}{l}\text { Type } \\
\text { of soil }\end{array}$} & \multirow{2}{*}{\multicolumn{2}{|c|}{ Parameter }} & \multirow{2}{*}{\multicolumn{2}{|c|}{$\begin{array}{l}\text { Normalization } \\
-\end{array}$}} & \multirow{3}{*}{$\begin{array}{l}\text { Fuzzy } \\
\text { c-means }\end{array}$} \\
\hline \multirow{2}{*}{$\begin{array}{l}\text { Lower } \\
\text { limit }\end{array}$} & \multirow{2}{*}{$\begin{array}{l}\text { Upper } \\
\text { limit }\end{array}$} & \multirow{2}{*}{$\begin{array}{l}\text { Lower } \\
\text { limit }\end{array}$} & \multirow{2}{*}{$\begin{array}{l}\text { Upper } \\
\text { limit }\end{array}$} & & & & & & & & \\
\hline & & & & & & & LL & IP & $\mathrm{BB}$ & AA & \\
\hline 856 & 2084 & 1.0000 & 1.0000 & Cluster_4 & 0.80 & ML & 41.26 & 17.29 & 0.825200 & 0.691600 & Cluster_3 \\
\hline 356 & 552 & 0.4151 & 0.2642 & Cluster_1 & 1.30 & ML & 37.71 & 20.67 & 0.754200 & 0.826800 & Cluster_3 \\
\hline 229 & 356 & 0.2665 & 0.1701 & Cluster_2 & 2.40 & ML & 37.77 & 2.93 & 0.755400 & 0.117200 & Cluster_4 \\
\hline 147 & 229 & 0.1706 & 0.1091 & Cluster_2 & 1.20 & ML & 31.43 & 3.05 & 0.628600 & 0.122000 & Cluster_4 \\
\hline 95.3 & 147 & 0.1101 & 0.0697 & Cluster_2 & 1.85 & ML & 45.27 & 21.32 & 0.905400 & 0.852800 & Cluster_3 \\
\hline 61.4 & 95.3 & 0.0704 & 0.0449 & Cluster_3 & 1.00 & $\mathrm{CH}$ & 50.83 & 26.04 & 0.016600 & 0.013867 & Cluster_1 \\
\hline 39.6 & 61.4 & 0.0449 & 0.0286 & Cluster_3 & 0.90 & $\mathrm{CH}$ & 54.29 & 27.54 & 0.085800 & 0.033867 & Cluster_1 \\
\hline 25.5 & 39.6 & 0.0285 & 0.0181 & Cluster_3 & 1.00 & $\mathrm{CH}$ & 57.06 & 31.60 & 0.141200 & 0.088000 & Cluster_1 \\
\hline 16.4 & 25.5 & 0.0178 & 0.0114 & Cluster_3 & 2.80 & $\mathrm{CH}$ & 55.55 & 29.61 & 0.111000 & 0.061467 & Cluster_1 \\
\hline 10.6 & 16.4 & 0.0110 & 0.0070 & Cluster_3 & 0.90 & CL & 55.11 & 15.41 & 0.880196 & 0.143108 & Cluster_4 \\
\hline 6.83 & 10.6 & 0.0066 & 0.0042 & Cluster_3 & 2.00 & CL & 58.08 & 20.58 & 0.821961 & 0.073243 & Cluster_4 \\
\hline 856 & 2084 & 1.0000 & 1.0000 & Cluster_4 & 0.55 & ML & 36.37 & 13.65 & 0.727400 & 0.546000 & Cluster_3 \\
\hline 552 & 856 & 0.6444 & 0.4102 & Cluster_1 & 0.95 & ML & 32.01 & 11.95 & 0.640200 & 0.478000 & Cluster_3 \\
\hline 356 & 552 & 0.4151 & 0.2642 & Cluster_1 & 1.95 & $\mathrm{CH}$ & 56.18 & 28.61 & 0.123600 & 0.048133 & Cluster_1 \\
\hline 229 & 356 & 0.2665 & 0.1701 & Cluster_2 & 0.75 & $\mathrm{CH}$ & 58.16 & 30.06 & 0.163200 & 0.067467 & Cluster_1 \\
\hline 147 & 229 & 0.1706 & 0.1091 & Cluster_2 & 0.85 & $\mathrm{CH}$ & 66.55 & 39.86 & 0.331000 & 0.198133 & Cluster_2 \\
\hline 95.3 & 147 & 0.1101 & 0.0697 & Cluster_2 & 0.50 & ML & 28.51 & 15.19 & 0.570200 & 0.607600 & Cluster_3 \\
\hline 61.4 & 95.3 & 0.0704 & 0.0449 & Cluster_3 & 0.90 & ML & 35.22 & 14.41 & 0.704400 & 0.576400 & Cluster_3 \\
\hline 39.6 & 61.4 & 0.0449 & 0.0286 & Cluster_3 & 1.45 & ML & 29.92 & 11.39 & 0.598400 & 0.455600 & Cluster_3 \\
\hline 25.5 & 39.6 & 0.0285 & 0.0181 & Cluster_3 & 1.90 & ML & 27.07 & 2.76 & 0.541400 & 0.110400 & Cluster_4 \\
\hline 16.4 & 25.5 & 0.0178 & 0.0114 & Cluster_3 & 1.35 & $\mathrm{CH}$ & 57.17 & 31.63 & 0.143400 & 0.088400 & Cluster_1 \\
\hline 10.6 & 16.4 & 0.0110 & 0.0070 & Cluster_3 & 1.20 & $\mathrm{CH}$ & 62.89 & 36.05 & 0.257800 & 0.147333 & Cluster_2 \\
\hline 6.83 & 10.6 & 0.0066 & 0.0042 & Cluster_3 & 1.55 & $\mathrm{CH}$ & 55.01 & 28.24 & 0.100200 & 0.043200 & Cluster_1 \\
\hline 4.4 & 6.83 & 0.0038 & 0.0024 & Cluster_3 & 1.10 & $\mathrm{CH}$ & 63.45 & 28.11 & 0.716667 & 0.028514 & Cluster_4 \\
\hline 856 & 2084 & 1.0000 & 1.0000 & Cluster_4 & 0.75 & ML & 36.62 & 14.76 & 0.732400 & 0.590400 & Cluster_3 \\
\hline 356 & 552 & 0.4151 & 0.2642 & Cluster_1 & 1.05 & $\mathrm{CH}$ & 57.99 & 29.89 & 0.159800 & 0.065200 & Cluster_1 \\
\hline 229 & 356 & 0.2665 & 0.1701 & Cluster_2 & 1.70 & $\mathrm{CH}$ & 62.56 & 34.12 & 0.251200 & 0.121600 & Cluster_2 \\
\hline 147 & 229 & 0.1706 & 0.1091 & Cluster_2 & 1.60 & ML & 31.23 & 3.62 & 0.624600 & 0.144800 & Cluster_4 \\
\hline 95.3 & 147 & 0.1101 & 0.0697 & Cluster_2 & 0.40 & ML & 34.52 & 3.56 & 0.690400 & 0.142400 & Cluster_4 \\
\hline 61.4 & 95.3 & 0.0704 & 0.0449 & Cluster_3 & 0.95 & CL & 57.58 & 20.89 & 0.441842 & 0.124400 & Cluster_2 \\
\hline 39.6 & 61.4 & 0.0449 & 0.0286 & Cluster_3 & 1.05 & $\mathrm{CH}$ & 62.04 & 35.18 & 0.240800 & 0.135733 & Cluster_2 \\
\hline 22.5 & 39.6 & 0.0285 & 0.0181 & Cluster_3 & 1.00 & $\mathrm{CH}$ & 56.67 & 31.24 & 0.133400 & 0.083200 & Cluster_1 \\
\hline 16.4 & 25.5 & 0.0178 & 0.0114 & Cluster_3 & 2.50 & $\mathrm{CH}$ & 66.76 & 38.78 & 0.335200 & 0.183733 & Cluster_2 \\
\hline 10.6 & 16.4 & 0.0110 & 0.0070 & Cluster_3 & 1.00 & $\mathrm{CH}$ & 62.92 & 34.48 & 0.258400 & 0.126400 & Cluster_2 \\
\hline 4.4 & 6.83 & 0.0038 & 0.0024 & Cluster_3 & 10.10 & $\mathrm{CH}$ & 53.50 & 26.81 & 0.070000 & 0.024133 & Cluster_1 \\
\hline 147 & 229 & 0.1706 & 0.1091 & Cluster_2 & 0.85 & $\mathrm{CH}$ & 62.19 & 38.58 & 0.243800 & 0.181067 & Cluster_2 \\
\hline 95.3 & 147 & 0.1101 & 0.0697 & Cluster_2 & 1.25 & $\mathrm{CH}$ & 58.32 & 33.15 & 0.166400 & 0.108667 & Cluster_1 \\
\hline 61.4 & 95.3 & 0.0704 & 0.0449 & Cluster_3 & 1.35 & $\mathrm{CH}$ & 60.31 & 32.89 & 0.206200 & 0.105200 & Cluster_1 \\
\hline 39.6 & 61.4 & 0.0449 & 0.0286 & Cluster_3 & 0.80 & $\mathrm{CH}$ & 65.92 & 36.78 & 0.318400 & 0.157067 & Cluster_2 \\
\hline 25.5 & 39.6 & 0.0285 & 0.0181 & Cluster_3 & 1.20 & $\mathrm{CH}$ & 55.15 & 29.72 & 0.103000 & 0.062933 & Cluster_1 \\
\hline 16.4 & 25.5 & 0.0178 & 0.0114 & Cluster_3 & 1.00 & $\mathrm{CH}$ & 57.83 & 29.93 & 0.156000 & 0.065733 & Cluster_1 \\
\hline 10.6 & 16.4 & 0.0110 & 0.0070 & Cluster_3 & 1.35 & $\mathrm{CH}$ & 56.09 & 28.84 & 0.121800 & 0.051200 & Cluster_1 \\
\hline 6.38 & 10.6 & 0.0066 & 0.0042 & Cluster_3 & 10.50 & $\mathrm{CH}$ & 61.00 & 37.25 & 0.220000 & 0.163333 & Cluster_2 \\
\hline 4.4 & 6.83 & 0.0038 & 0.0024 & Cluster_3 & 1.80 & ML & 32.39 & 13.96 & 0.647800 & 0.558400 & Cluster_3 \\
\hline 2.83 & 4.4 & 0.0019 & 0.0012 & Cluster_3 & 2.20 & ML & 41.50 & 24.7 & 0.830000 & 0.988000 & Cluster_3 \\
\hline 1.82 & 2.83 & 0.0007 & 0.0005 & Cluster_3 & 0.75 & ML & 37.45 & 14.13 & 0.749000 & 0.565200 & Cluster_3 \\
\hline 1.18 & 1.82 & 0.0000 & 0.0000 & Cluster_3 & 1.40 & ML & 41.92 & 18.17 & 0.838400 & 0.726800 & Cluster_3 \\
\hline
\end{tabular}

the result of normalization of the lowest limit of 0.6444 of 4 members. Cluster 2 which represents the normalization result of the lowest limit of 0.1101 and the result of normalization of the lowest limit of 0.2665 as many as 11 members. Cluster 3 which represents the value of the lowest limit normalization result 0.0066 and the result of the lowest limit normalization 0.0704 of 29 members. Cluster 4 which represents the normalization result of the lowest lower limit of 1.100 and the results of the normalization of the highest lower limit of 1.0000 is 3 members. Whereas the results of the cluster are at upper boundary georesistivity. Cluster 1 which represents the normalized value of the lowest upper limit of 0.2642 and the results of the normalized upper limit of the highest 0.4102 of 4 members. Cluster 2 which represents the normalized value of the lowest upper limit of 0.0697 and the result of normalization of the highest upper limit of 0.1701 totaling 11 members. Cluster 3 which represents the value of the normalization result of the lowest upper limit of 0.0042 and the results of the normalization of the 


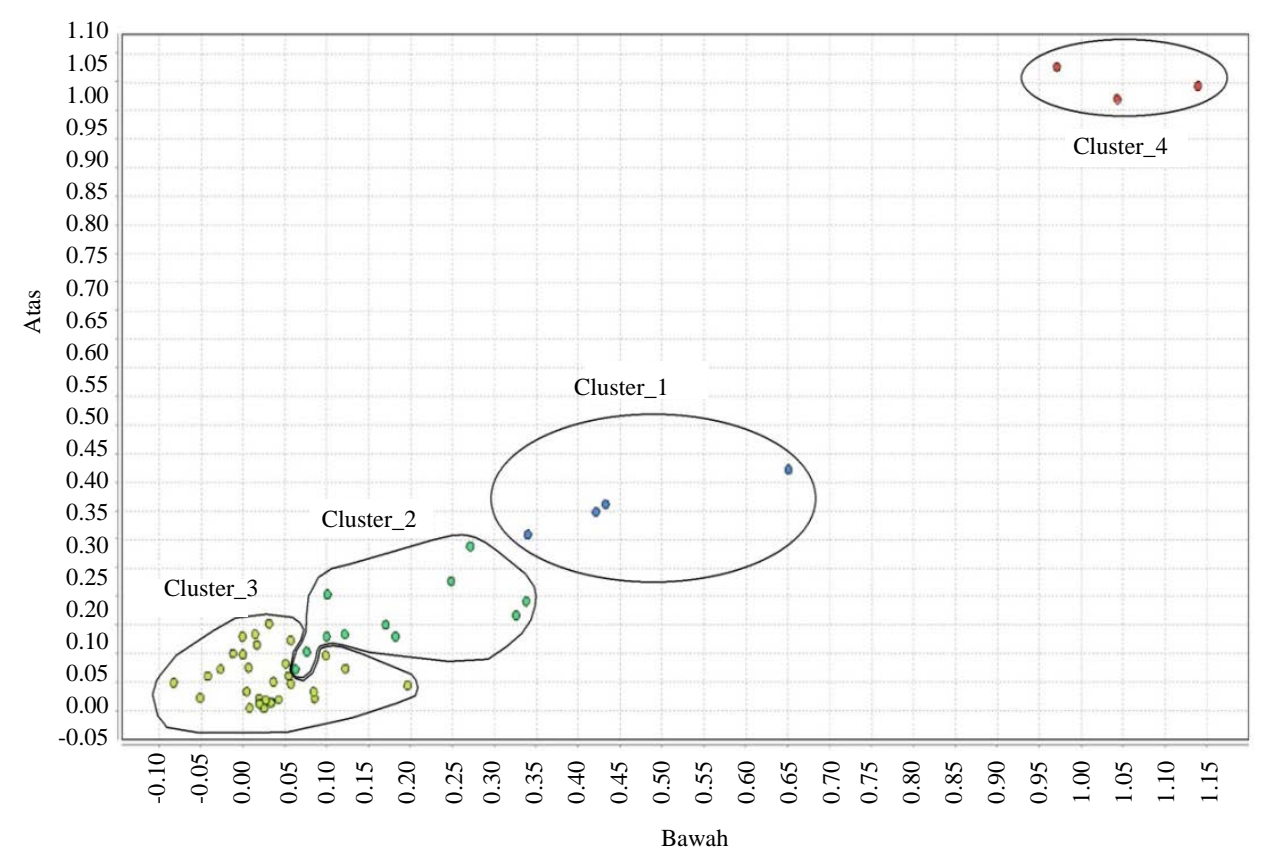

Fig. 1: Distribution of georesistivity cluster members

highest upper limit of 0.0449 as many as 29 members. Finally, cluster 4 that represents the normalized value of the lowest upper limit of 1,0000 and the results of the normalization of the highest upper limit of 1,0000 is 3 members. The results of the cluster in engineering geology show that, cluster 1 which represents the normalized value of the lower limit BB normalization of 0.100200 and the normalization result of the highest upper limit BB of 0.206200 is 16 members. Cluster 2 which represents the value of the normalization result of the lower limit BB of 0.220000 and the result of normalization of the highest limit of $\mathrm{BB}$ of 0.441842 is 10 members. Cluster 3 which represents the normalized value of the lower limit BB norms of 0.570200 and the normalized upper limit BB results of 0.838400 totaling 12 members. Finally, cluster 4 which represents the normalized value of the lower limit BB is 0.541400 and the normalized result of the upper limit BB is 0.880196 with 8 members. Whereas the results of the cluster in engineering geology for AA cluster 1 representing the value of the results of the normalization of the lowest lower limit of AA 0.013867 and the results of the normalization of the upper limit of the highest 0.108667 were 16 members. Cluster 2 which represents the value of the normalization results of the lowest lower limit of AA 0.121600 and the results of the normalization of the highest upper limit of AA is 0.198133 as many as 10 members. Cluster 3 which represents the value of the lowest limit AA normalization results 0.478000 and the highest upper limit AA normalization results of 0.988000 as many as 13 members. Finally, cluster 4 which represents the value of the normalization result of the lowest lower limit of 0.028514 and the result of the normalization of the highest upper limit of 0.144800 is 8 members. From Fig. 1 the results of the cluster to see the distribution of group members as a whole which shows cluster 1 represented by blue contained in BH-01 with 1 member, BH-02 with 2 members and $\mathrm{BH}-03$ with 1 member. Cluster 2 is represented by green which is found in BH-01 with 3 members, $\mathrm{BH}-02$ with 3 members, $\mathrm{BH}-03$ with 6 members and $\mathrm{BH}-04$ with 2 members. Cluster 3 is represented by the yellow color found in $\mathrm{BH}-01$ with 6 members, BH-02 with 7 members, BH-03 with 6 members and BH-04 with 10 members. Finally, cluster 4 is represented by red in $\mathrm{BH}-01$ with 1 member, $\mathrm{BH}-02$ with 1 member, $\mathrm{BH}-03$ with 1 member and $\mathrm{BH}-04$ with 0 members. From Fig. 2 the results of the cluster after drilling up to $15 \mathrm{~m}$ shows the distribution of members to see the distribution of group members as a whole shows that in $\mathrm{BH}-01$ for cluster 1 which is represented by blue there are 3 types of soil $\mathrm{ML}, \mathrm{CH}$ and CL with 16 members, BH-02 for cluster 2 represented by green in which there are 2 types of $\mathrm{ML}$ and $\mathrm{CH}$ soil with 10 members, $\mathrm{BH}-03$ for cluster 3 which is represented by yellow containing 3 types of ML, CH and CL with 13 members, $\mathrm{BH}-04$ for cluster 4 which is represented by red which contains 2 types of $\mathrm{CH}$ and ML soil with 8 members. 


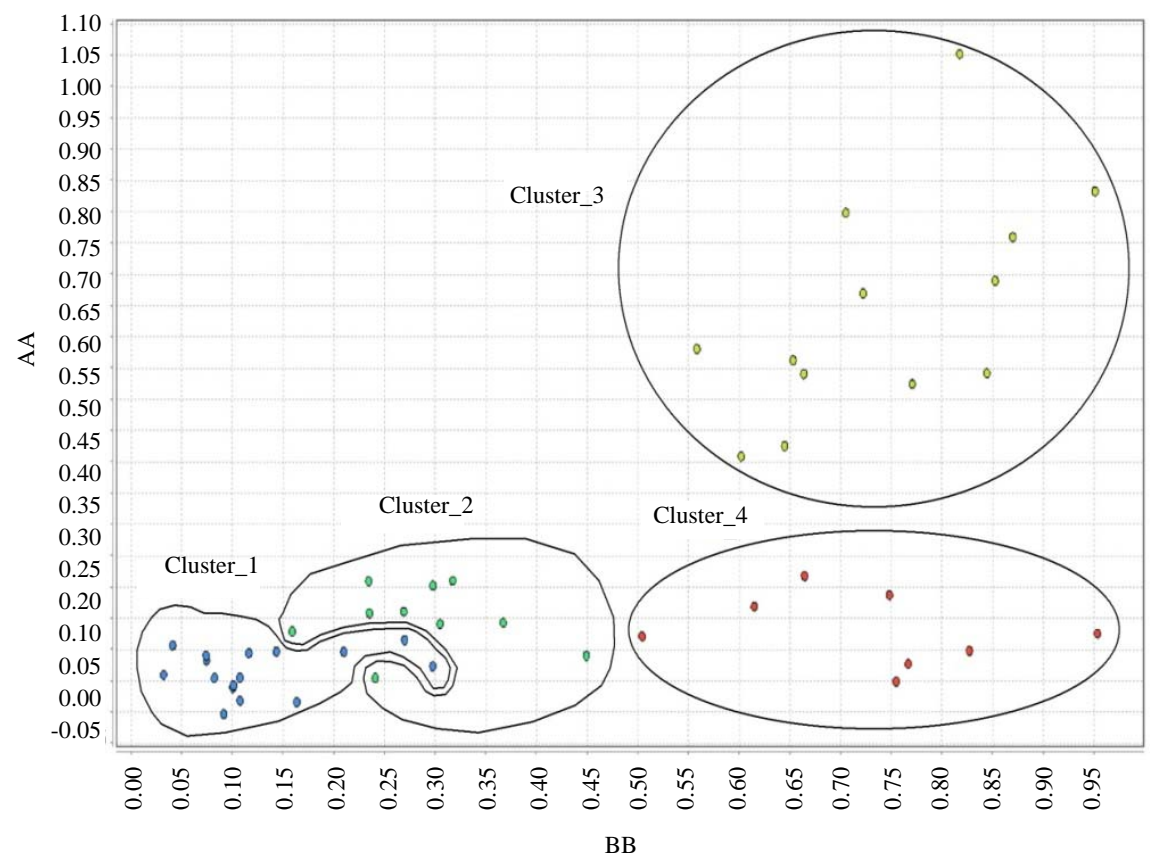

Fig. 2: Distribution of members of the engineering geology cluster

\section{CONCLUSION}

From the results of the investigation found that the surface soil layer was found to a depth of $15 \mathrm{~m}$. The top surface that has the highest resistivity value reaches 856-084 $\Omega \mathrm{m}$ and the lowest resistivity value is 1.18-1.82 $\Omega \mathrm{m}$ according to its constituent material. The results of the dominant laboratory analysis are gray-gray and black-gray clay which indicates that at a certain depth in the study site there are 4 types of soil.

In all 1-4 clusters of processes in this georesistivity there are different types of soil. This means that in clusters there are no dominant soil types. Likewise, the results of clusters in engineering geology show that soil types are mixed in each cluster.

\section{ACKNOWLEDGEMENTS}

The researcher of contract number 20161141010478 would like to thank the LPDP (Educational Fund Management Agency) for providing financial support to this research, until the study was completed on time.

\section{REFERENCES}

AL-Shuhail, A.R., 2008. Integration of surface seismic data with geo-electric data. M.Sc. Thesis, Earth Sciences Department King Fahd Univesity of Petroleum \& Minerals, Saudi Arabia.
Bezdek, J.C., 1981. Pattern Recognition with Fuzzy Objective Function Algoritms. 1st Edn., Plenum Press, New York, USA.

Cosenza, P., E. Marmet, F. Rejiba, Y.J. Cui, A. Tabbagh and Y. Charlery, 2006. Correlations between geotechnical and electrical data: A case study at Garchy in France. J. Applied Geophys., 60: 165-178.

Danielsen, B.E. and T. Dahlin, 2010. The applicability of geoelectrical methods in pre-investigation for construction in rock. Ph.D. Thesis, Engineering Geology Lund University, Sweden.

Dieudonne, E.P., S. Ganno and T.T. Charles, 2012. Geophysical and geotechnical investigations of a landslide in Kekem Area, Western Cameroon. Int. J. Geosci., 3: 780-789.

Fatoba, J.O., J.O. Alo and A.A. Fakeye, 2010. Geoelectric imaging for foundation failure investigation at Olabisi Onabanjo University (O.O.U) mini campus, Ago Iwoye, Southwestern Nigeria. J. Applied Sci. Res., 6: 2192-2198.

Jain, A.K., M.N. Murty and P.J. Flynn, 1999. Data clustering: A review. ACM Comput. Surv., 31: 264-323.

Kusumadewi, S. and H. Purnomo, 2010. Fuzzy logic application for decission support system. Graha Ilmu Press, Jakarta, Indonesia. 
Lantu, D.A. Suriamihardja, A.M. Imran and T. Harianto, 2014. Relationship between electrical and mechanical properties of subsurface under the ground. Proceedings of the 4th International Conference on Theorical and Applied Physics (ICTAP'14), October 16-17, 2014, Bali, Indonesia, pp: 9345-9352.

Raj, A.S., D.H. Oliver and Y. Srinivas, 2015. Geoelectrical data inversion by clustering techniques of fuzzy logic to estimate the subsurface layer model. Int. J. Geophys., Vol. 2015, 10.1155/2015/134834

Reynolds, J.M., 2011. An Introduction to Applied and Environmental Geophysics. 2nd Edn., Wiley Publishing Company, Hoboken, New Jersey, USA., ISBN:978-0-471-48535-3, Pages: 710.

Roubens, M., 1982. Fuzzy clustering algorithms and their cluster validity. Eur. J. Oper. Res., 10: 294-301.
Siddiqui, F.I. and S. Osman, 2012. Integrating geo-electrical and geotechnical data for soil characterization. Int. J. Applied Phys. Math., 2: 104-106.

Suganya, R. and R. Shanthi, 2012. Fuzzy C-means algorithm-a review. Int. J. Sci. Res. Publ., Vol. 2, No. 11.

Telford, W.M., L.P. Geldart and R.E. Sheriff, 1990. Applied Geophysic. 2nd Edn., Cambridge University Press, New York, USA., ISBN: 9781139642927, Pages: 1269.

Zimmermann, H.J., 2001. Fuzzy Set Theory and its Applications. 4th Edn., Springer, Boston, ISBN-13:978-0792374350, Pages: 544. 